\title{
IDENTIFIKASI PENGENDALIAN PEMANFAATAN RUANG MELALUI INSTRUMEN INSENTIF DAN DISINSENTIF PADA KAWASAN PARIWISATA PESISIR DI PANTAI AMAHAMI DAN NI'U
}

\author{
Anggun Wardenia, Fariz Primadi Hirsan \\ Program Studi Teknik Perencanaan Wilayah dan Kota Fakultas Teknik Universitas Muhammadiyah Mataram \\ Ang9unwardenia@gmail.com
}

\begin{tabular}{l}
\hline INFO ARTIKEL \\
\hline Riwayat Artikel: \\
Diterima: 04-1 1-2017 \\
Disetujui: 28-01-2018
\end{tabular}

\section{Kata Kunci:}

Pengendalian Pemanfaatan Ruang Insentif dan Disinsentif Pariwisata Pesisir

\begin{abstract}
ABSTRAK
Abstrak: Pengendalian pemanfaatan ruang pada kawasan pariwisata pesisir pantai Amahami dan Ni'u perlu dilakukan mengingat daerah tersebut merupakan salah satu kawasan strategis pariwisata dan kawasan strategis perekonomian yang adaS di Kota Bima, dengan dilakukannya suatu pengendalian diharapkan pemanfaatan ruang yang ada pada kawasan tersebut dapat berjalan sesuai dengan rencana pola ruang Rasanae Barat, salah satu instrumen yang tepat untuk digunakan selain peraturan zonasi adalah instrumen insentif dan disinsentif, dimana instrumen insentif diberikan kepada pemerintah ataupun masyarakat yang taat dan tertib terhadap tata ruang, sedangkan disinsentif diberikan kepada pemerintah ataupun masyarakat yang tidak tertib atau melanggar tata ruang.
\end{abstract}

\begin{abstract}
Control of spatial use in coastal tourism area of Amahami and Ni'u needs to be done considering that the area is one of strategic area of tourism and strategic area of economy in Bima City, by doing a control is expected to utilization of existing space in the area can run in accordance with the West Rasanae spatial plan, one of the right instruments for use other than the zoning regulation is the incentive and disincentive instrument, where the incentive instrument is given to the government or a devout and orderly society to the spatial, while the disincentive is given to the government or society that is not orderly or violate spatial.
\end{abstract}

\section{A. PENDAHULUAN}

Kawasan pesisir pantai Ni'u dan Amahami yang berfungsi sebagai kawasan pariwisata juga terdapat pemanfaatan ruang sebagai kawasan perdagangan serta jasa. Hal ini juga telah ditetapkan pada Perda No. 4 tahun 2012 tentang Rencana Tata Ruang Wilayah Kota Bima Tahun 2011 - 2031 [1].

Kawasan pariwisata pesisir di pantai Amahami dan Ni'u merupakan salah satu kawasan strategis pariwisata, hal ini berdasarkan pada Perda No. 4 tahun 2012 tentang Rencana Tata Ruang Wilayah Kota Bima Tahun 2011 2031. Pantai Amahami dan Ni'u yang berada di wilayah Kota Bima memiliki luas wilayah 22,25 $\mathrm{km}^{2}$, dibandingkan dengan pantai-pantai lainnya seperti pantai Ule dan pantai Kolo, letak pantai Amahami dan Ni'u lebih strategis karena berada pada pintu masuk utama Kota Bima [1].

Namun pada kenyataanya kawasan yang telah ditetapkan dalam Peraturan Daerah sebagai kawasan pariwisata tersebut justru terdapat peruntukan yang tidak sesuai dengan arahan pemanfaatan tata ruang, yang seharusnya dalam Perda No. 4 tahun 2012 tentang Rencana Tata Ruang Wilayah Kota Bima Tahun 2011-
2031 menyatakan wilayah Pantai Amahami dan Ni’u sebagai kawasan pariwisata dan perdagangan dan jasa [1]. Kondisi ini mengisyaratkan bahwa untuk mewujudkan terciptanya pembangunan yang sesuai dengan tata ruang diperlukan tindakan pengendalian pemanfaatan ruang yang sungguh-sungguh.

Mekanisme insentif dan disinsentif yang merupakan salah satu instrumen pengendalian pemanfaatan ruang yang tertuang dengan jelas pada UU No.26 tahun 2007 dianggap mampu untuk mendorong perkembangan kota dan dapat menimbulkan dampak positif yang menunjang pembangunan kota atau upaya pengarahan pada perkembangan yang berdampak positif untuk mengefektifkan pembangunan/rencana tata ruang yang telah ditetapkan.

\section{RUMUSAN MASALAH}

$>$ Bagaimana kondisipengendalian pemanfaatan ruang yang telah berjalan pada kawasan pariwisata pesisir pantai Amahami dan Ni'u?

$>$ Bagaimana mekanisme pengendalian pemanfaatan ruang di kawasan pariwisata 
pesisir pantai Amahami dan Ni'u berdasarkan instrumen insentif dan disinsentif?

\section{TUJUAN}

$>$ Untuk mengetahui kondisi pengendalian pemanfaatan ruang yang telah berjalan pada kawasan pariwisata pesisir pantai Amahami dan Ni'u.

> Untuk merumuskan mekanisme pengendalian pemanfaatan ruang di kawasan pariwisata pesisir pantai Amahami dan Ni'u berdasarkan instrumen insentif dan disinsentif

\section{B. METODE PENELITIAN}

\section{LOKASI DAN WAKTU PENELITIAN}

Penelitian ini dilaksanakan di Kelurahan Dara Kecamatan Rasanae Barat Kota Bima, Propinsi Nusa Tenggara Barat. Penelitian ini dilakukan selama empat bulan yang dimulai dari bulan Maret Tahun 2017 sampai dengan bulan Juni tahun 2017

\section{PENDEKATAN PENELITIAN}

Pendekatan penelitian yang digunakan pada penelitian ini adalah pendekatan yuridis normatif. Pendekatan yuridis normatif dilakukan terhadap nilai dan norma hukum untuk mempelajari kaedah hukum yang dengan mempelajari, menelaah, peraturan perundang-undangan dan konsep-konsep yang berhubungan dengan masalah yang akan dibahas.

\section{Sifat Penelitian}

Sifat penelitian yang digunakan adalah deskriptif yaitu penelitian yang menggambarkan serta menjelaskan suatu keadaan yang diperoleh melalui penelitian di lapangan

\section{PENGUMPULAN DATA}

a) Data primer

$>$ Observasi Lapangan dan DokumentasiPengumpulan data yang dilakukan melalui observasi lapangan dan dokumentasi yaitu kegiatan melihat secara langsung pada kawasan penelitian yang bertujuan untuk mengetahui kondisi yang terjadi saat ini, sebagai gambaran mengenai kawasan penelitian dan bertujuan untuk mendapatkan data visual pada kawasan penelitian.

> Adapun sesi wawancara yang merupakan metode pengumpulan data dengan jalan tanya jawab sepihak yang dilakukan secara sistematis dan berlandaskan kepada tujuan penelitian, pada sesi wawancara berbentuk wawancara tak terstruktur dikarenakan pewawancara atau peneliti tidak memberikan pilihan jawaban kepada responden

b) Data Sekunder
Merupakan upaya pengumpulan data yang dilakukan melalui instansi terkait seperti Dinas PU Kota Bima, BAPPEDA Kota Bima, Dinas Tata Kota Bima, Dinas

Pariwisata dan bahan-bahan hukum yang terdiri dari:

$>$ Undang-undang Nomor 26 Tahun 2007 tentang Penataan Ruang.

> Peraturan Pemerintah Nomor 26 Tahun 2008 Tentang Rencana Tata Ruang Wilayah Nasional.

> Peraturan Daerah Kota Bima Nomor 4 Tahun 2012 tentang Rencana Tata Ruang Wilayah Kota Bima Tahun 2011-2031.

$>$ Undang-undang Nomor 10 tahun 2009 tentang kepariwisataan

$>$ Undang-undang Nomor.27 tahun 2007 tentang pengelolaan pesisir dan pulau-pulau kecil

\section{TEKNIK PENGOLAHAN DATA DAN ANALISIS} DATA

a) Pengolahan Data

b) Pengolahan data dilakukan dengan cara editing yaitu data yang diperoleh akan diedit terlebih dahulu guna mengetahui apakah data-data yang diperoleh tersebut sudah cukup baik dan lengkap untuk mendukung pemecahan masalah yang sudah dirumuskan.

c) Analisis Kebijakan Publik

d) Analisis Kebijakan Publik yaitu Cara untuk mensintesakan informasi, termasuk hasil penelitian, untuk menghasilkan format keputusan kebijakan (penentuan pilihanpillihan alternatif) dan untuk menentukan kebutuhan masa depan akan informasi yang policy relevant (Walter Williams, 1971).

e) Analisis Deskriptif Kualitatif

f) Penelitian kualitatif bertujuan untuk mengetahui aktualitas, realitas sosial dan persepsi manusia melalui pengakuan mereka, yang mungkin tidak dapat diungkapkan melalui penonjolan pengukuran formal atau pertanyaan penelitian yang telah dipersiapkan terlebih dahulu. (Wolf dan Tymiz dalam sukardi (2006: 2).

\section{RUANG LINGKUP PENELITIAN}

Ruang lingkup penelitian hanya dilakukan disepanjang koridor pantai Amahami dan Ni'u, pengambilan yang menjadi dasar lokus penelitian adalah dikarenakan kawasan Amahami Niu merupakan salah satu kawasan strategis pariwisata dan perekonomian dan berada pada gerbang utama Kota Bima serta dikarenakan adanya isu-isu strategis pembangunan kepariwisataan yang akan dilakukan disepanjang kawasan Amahami dan Ni'u dalam menjadi Kawasan Amahami sebagai sebuah wajah kota Bima. 


\section{VARIABEL PENELITIAN}

Berdasarkan teori tersebut maka dapat disimpulkan variabel penelitian merupakan atribut/sifat/nilai dari orang/obyek/kegiatan yang mempunyai variasi tertentu yang ditetapkan oleh peneliti untuk dipelajari dan ditarik kesimpulannya.

Tabel 1. VARIABEL PENELITIAN

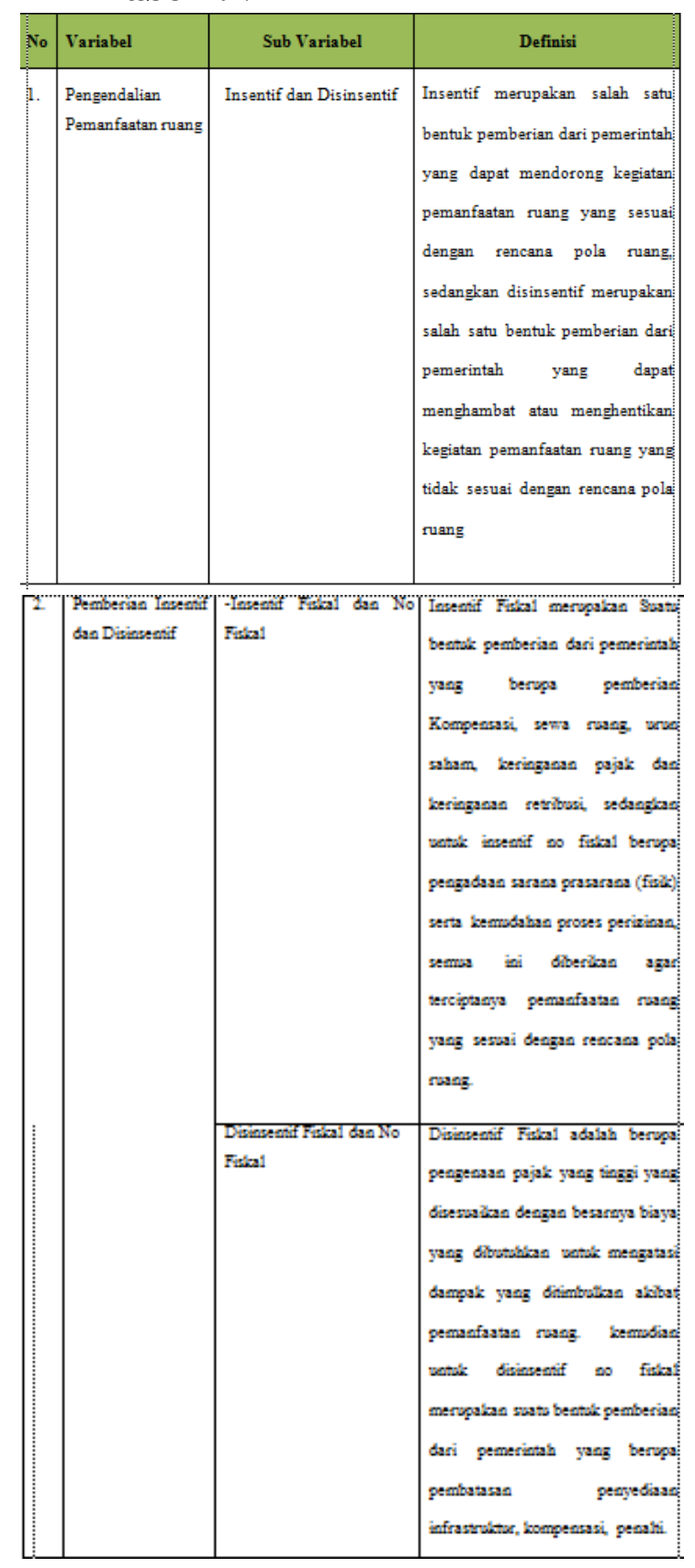

\section{GAMBARAN UMUM DAN PEMBAHASAN}

\section{IDENTIFIKASI LOKASI PENELITIAN}

Untuk mengidentifikasi lokasi penelitian, dibagi menjadi dua jenis kondisi fisik lokasi penelitian, yaitu kondisi fisik dasar, yang dimana pembahasan untuk kondisi fisik dasar mengidentifikasi terkait kondisi geografis, kondisi topografi, kondisi geologi, kondisi tata guna lahan, serta kondisi DAS di lokasi penelitian, dan untuk kondisi fisik binaan di fokuskan pada mengidentifikasi kondisi kependudukan, kondisi utilitas jaringan, dan kondisi pariwisata yang berada di lokasi penelitian.

a. Rencana Pola Ruang

Rencana Pola Ruang Rasanae Barat merupakan suatu kecamatan yang ada di Kota Bima yang merupakan kecamatan dari lokasi penelitian dan juga merupakan suatu kawasan strategis pariwisata dan kawasan utama sektor perekonomian, hal itu telah tertuang dengan jelas pada RTRW dan RDTR Kota Bima Tahun 2011-2031. Pola ruang kawasan Rasanae Barat terdiri dari beberapa peruntukan ruang seperti perdagangan dan jasa, permukiman serta pariwisata.

Rencana Pola Ruang Kawasan Amahami Niu diindikasikan sebagai alokasi ruang untuk berbagai kegiatan sosial ekonomi masyarakat dan kegiatan pariwisata berbasis lingkungan alam dalam wilayah kota Bima. Rencana pola ruang untuk wilayah perkotaan sseperti daerah Amahami dan Ni'u dirumuskan berdasarkan beberapa hal antara lain yaitu kebijakan dan strategi penataan ruang wilayah kota, daya dukung dan daya tampung lingkungan hidup wilayah kota, kebutuhan ruang untuk pengembangan kegiatan sosial ekonomi dan lingkungan dan ketentuan peraturan perundangundangan terkait.

b. Mekanisme Pemberian Insentif dan Disinsentif Pada Kawasan Amahami dan Ni'u

$>$ Analisis Kebijakan Publik

Analisis kebijakan publik menggunakan alat ukur berupa matriks persandingan, yang dimana peneliti mengidentifikasi kesesuaian kondisi eksisting pemanfaatan ruang kawasan Amahami Ni'u yang terkini disandingkan dengan Rencana Detail Tata Ruang (RDTR) Rasanae Barat, setelah mendapatkan hasilnya, peneliti disini juga mengidentifikasi faktorfaktor yang mendukung dan menghambat dalam pelaksanaan pengedalian pemanfaatan ruang, sehingga nantinya arahan dalam mekanisme pemberian Insentif dan Disinsentif dapat tepat sasaran sesuai dengan RDTR Rasanae Barat.

Dalam mengidentifikasi kesesuaian pemanfaatan ruang kawasan Amahami Ni'u diperlukan data mengenai kondisi terkini pemanfaatan ruang didaerah tersebut, dalam kawasan Amahami dan Ni'u pemanfaatan ruang yang terdapat berupa pariwisata, perekoniman, RTH, Perumahan, Pendidikan, Sempadan Pantai dan Industri, lalu kemudian disandingkan dengan data RDTR mengenai kawasan masing-masing.

$>$ Hasil Identifikasi Kesesuaian Pemanfaatan ruang dengan RDTR Rasanae Barat 
Tabel 2. HASIL IDENTIFIKASI KESESUAAN TERHADAP RDTR RASANAE BARAT

\begin{tabular}{|c|c|c|c|}
\hline Pois Rusag & Keveraegan & Pengzousan Laban & Hasd \\
\hline $\begin{array}{l}\text { Indostri dan } \\
\text { Pergudangan }\end{array}$ & Kamasan Bodidaya & Intussri & Sesosi \\
\hline Parminata & Kamasan Boskay & Babas & Semant \\
\hline Parmisata & Ramasan Bodidaya & Intostri & Serosi \\
\hline Pasquicas & 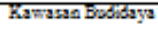 & Padang Vumpot: & Sensit \\
\hline Pasmisata & Ramasan Bodidaya & Peadidlean & Semosi \\
\hline Parmisata & Kamasan Bodidaya & $\begin{array}{c}\text { Perdagangan dan } \\
\text { Jasa }\end{array}$ & Sesosi \\
\hline Pasmiasa: & Ramasan Bodidaya & Perkebrosan & Sesosi \\
\hline Pasminata & Rawasan Boblisaya & Permakiman & Semosi \\
\hline Parminata & Kawasan Boblisaya & Semar Beblear & Sesonit \\
\hline Pasminata & Ramasan Bosidaya & Tegalan Ladang & Sesosi \\
\hline Pasmisata & 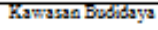 & Wasata & ङemant \\
\hline Peadidizan & Ramasan Bodidaya & Padang Rumput & Semsil \\
\hline Peoblitian & Kamasan Bodíaya & Pendiblan & Semast \\
\hline $\begin{array}{l}\text { Perdagangan dan } \\
\text { Jasa }\end{array}$ & Kamasan Bodidaya & $\begin{array}{c}\text { Perdagangan dan } \\
\text { Jasa }\end{array}$ & Semai \\
\hline Peraebroan & Kamasan Buslisaya & Padang Rumput & Semait \\
\hline Perketroas & Kamasan Bodidaya & Pedkebuase & Sensai \\
\hline Perkebrasn & 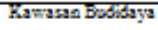 & Tegalan Ladang & Semat \\
\hline Permatkiman & Kamasan Bodidaya & Permatimas & Sesosi \\
\hline $\begin{array}{c}\text { Reacasa } \\
\text { Pengzeasa } \\
\text { Lainnya }\end{array}$ & Ramasan Bodidaya & $\begin{array}{c}\text { Padang Rumpot } \\
\text { Sersai }\end{array}$ & Sesosi \\
\hline $\begin{array}{c}\text { Rencasa } \\
\text { Penggroase } \\
\text { Lainaya }\end{array}$ & Ramasan Boditaya & Permukiman & Semosi \\
\hline
\end{tabular}

2. FAKTOR-FAKTOR

PENGHAMBAT

DAN PENDUKUNG DALAM PENGENDALIAN PEMANFAATAN RUANGPADA KAWASAN AMAHAMI NI'U BERDASARKAN INSENTIF DAN DISISNSENTIF

a. Faktor Pendukung

$>$ Potensi Pengembangan Fisik

Pantai Amahami dan Ni'u merupakandaerah pesisir pantai yang berpotens iuntuk pengembangan budidaya tambak, mangrove, dan ruang terbuka hijau, dari sini pemerintah dapat memberikan insentif terhadap pengembangan potensi fisik tersebut.

$>$ Potensi Pengembangan Ekonomi dan Pariwisata Seperti yang diketahui bersama sektor ekonomi dan pariwisata merupakan satu kesatuan sektor andalan dalam pengembangan kawasan pariwisata pesisir, jika dalam suatu kawasan telah berjalan sebuah kegiatan pariwisata maka kegiatan ekonomi akan jalan bersamaan, pengembangan ekonomi dan pariwisata pada kawasan pesisir pantai Amahami dan Ni'u berpotensi untuk wisata alam, perdagangan dan jasa serta berupa cafe dan restoran sambil berwisata alam, hal ini tentunya dapat diberikan insentif karena pemanfaatan ruang yang sesuai dengan RDTR.

b. Faktor Penghambat

$>$ Masalah Fisik Identifikasimasalahfisikmerupakanhalyangpenti nguntukdibahas dalam pengendalian pemanfaatan ruang, karena bias terjadi penggunaan lahan yang tidak sesuaian dengan peruntukannya sehingga memberikan hasil yang tidak optimal dan merugikan, masalah fisik seperti ini perlu diberikan disinsentif dalam mendukung pemanfaatan ruang yang sesuai dengan rencana tata ruang.

\section{Masalah Tata Ruang}

- TingkatpartisipasidanpendayagunaanRDTR masih rendah oleh masyarakat kawasan pariwisata pesisir pantai Amahami dan Ni'u.

- Kurangnya sosialisasi mengenai pengendalian pemanfaatan ruang dari aparat pemerintah untuk masyarakat kawasan pariwisata pesisir pantai Amahami dan Ni'u.

\section{ARAHAN PEMBERIAN INSENTIF DAN DISINSENTIF}

Dilihat dari segi penting dan bermanfaatnya suatu pemberian insentif dan disinsentif ini pada suatu kota, maka Kota Bima Perlu mengeluarkan regulasi yang khusus mengatur pemberian insentif dan disinsentif pada suatu kawasan pemanfaatan ruang secara lengkap. Setelah melakukan serangkaian analisis pada bab-bab sebelumnya maka disini peneliti memberikan beberapa arahan pemberian insentif dan disinsentifpada pemanfaatan ruang kawasan studi, adapun diantaranya berdasarkan kawasan, luas kawasan, tujuan pemberian insentif dan disinsentif pada suatu kawasan, bentuk insentif dan bentuk disinsentif yang diberikan pada suatu kawasan pemanfaatan ruang amahami Ni'u. Untuk lebih jelasnya dapat dilihat pada tabel dan peta insentif dan disinsentif dibawah :

Tabel 3. ARAHAN PEMBERIAN INSENTIF DAN DISINSENTIF

\begin{tabular}{|c|c|c|c|c|}
\hline Kamasan & $\begin{array}{c}\text { Losas Kamasas } \\
\text { (Ha) }\end{array}$ & Bentus Insensif & Bests Disinsensif & 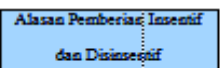 \\
\hline Pximinas & 4.11 & $\begin{array}{c}\text { Investif No } \\
\text { Futeal }\end{array}$ & - & 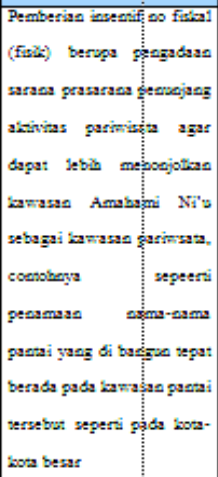 \\
\hline Penfminsimas & 1242 & 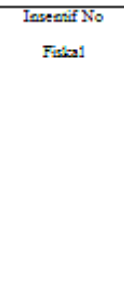 & - & 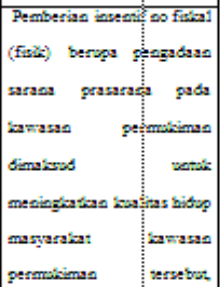 \\
\hline
\end{tabular}




\begin{tabular}{|c|c|c|c|c|c|}
\hline & & & & & 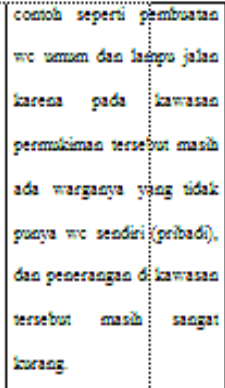 \\
\hline & & & & & 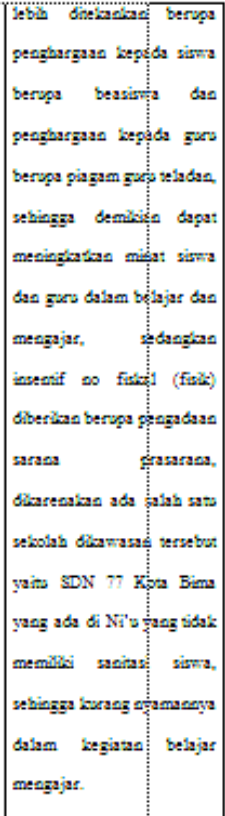 \\
\hline & $\mathrm{RTH}$ & 8.71 & $\begin{array}{c}\text { Ionesenif No } \\
\text { Fatsal }\end{array}$ & & 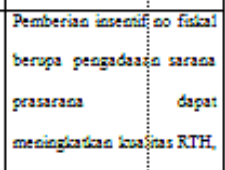 \\
\hline & & & & & 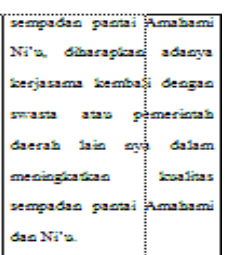 \\
\hline Tostssis & Pergasagagse & 5.75 & & 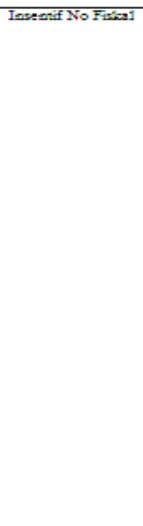 & 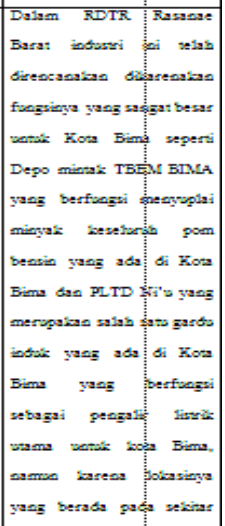 \\
\hline
\end{tabular}
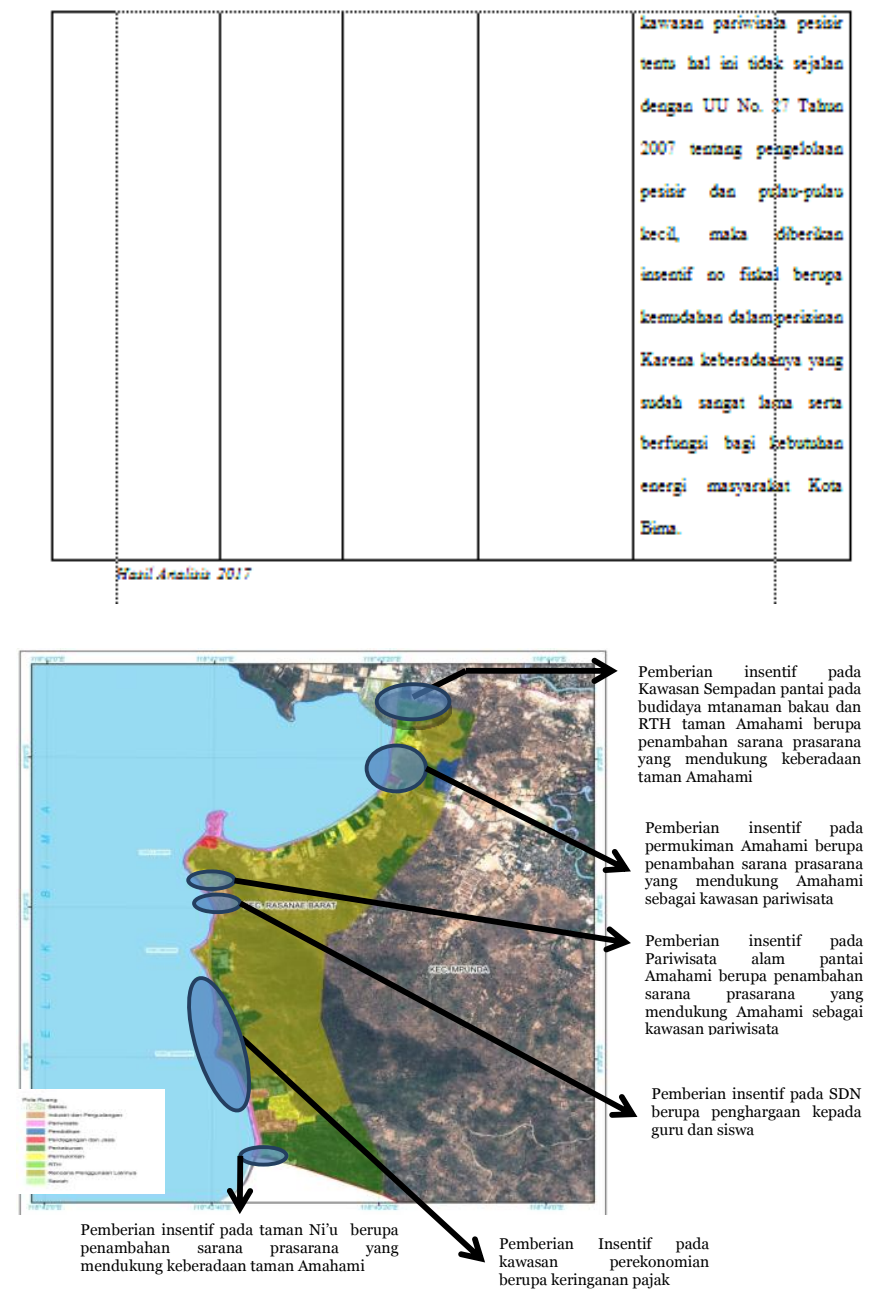

Gambar 1.Peta Insentif Amahami Ni’u

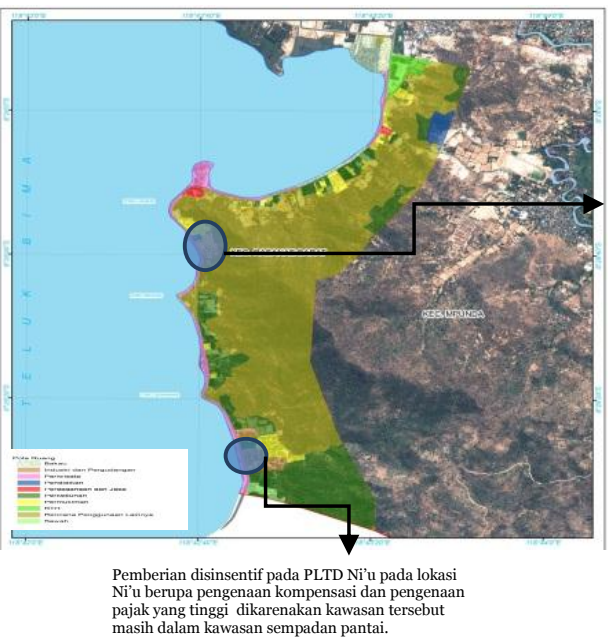

Pemberian disinsentif pada depo minyak dan gas pada pengenaan pajak yang tinggi dikarenakan kawasan
tersebut masih dalam

Gambar 2. Disinsentif Amahami Ni'u

\section{SIMPULAN DAN SARAN}

\section{KESIMPULAN}

$>$ Pengendalian pemanfaatan ruang melalui instrumen insentif dan disinsentif sangat membantu dalam pengembangan kawasan pariwisata pesisir pantai Amahami dan Ni'u, dikarenakan adanya pemberian Insentif yang dapat memacu keinginan investor ataupun masyarakat yang ingin melakukan kegiatan 
usaha yang bersangkutan dengan pariwisata pesisir pada daerah Amahami dan Ni'u.

$>$ Terdapat beberapa kesesuaian antara penggunaan lahan eksisting kawasan dengan Rencana Pola Ruang Amahami Ni'u.

$>$ Adapun pemanfaatan ruang yang tidak sesuai dengan kawasan pariwisata pesisir pada pantai Amahami dan Ni'u yaitu Industri/Pergudangan namun dapat diberikan tindakan berupa disinsentif fiskal yaitu dengan memberikan pajak yang tinggi pada industri/pergudangan tersebut.

$>$ Faktor pendukung dan penghambat pelaksanaan penataan ruang pada kawasan pariwisata pesisir pantai Amahami dan Ni'u yaitu pada faktor pendukungnya terdapat pengembangan potensi fisik, ekonomi dan pariwisata sedangkan pada faktor penghambatnya ditemukan masalah fisik dan masalah tata ruang.

> Dengan belum adanya diberikan Disinsentif pada kawasan pariwisata pesisir pantai Amahami dan Ni'u menandakan rencana pola ruang Rasanae Barat berjalan sesuai dengan pemanfaatan ruang yang terjadi saat ini.

2. SARAN

$>$ Bagi pemerintah Kota Bima

Pemerintah Kota Bima diharapkan dapat memberikan sosialisasi mendalam mengenai pengendalian pemanfaatan ruang terhadap masyarakat sekitar kawasan pariwisata pesisir Amahami dan Ni'u

> Bagi Program Studi PWK UMM

Agar dalam kegiatan perkuliahan dapat melakukan materi lebih mendalam mengenai Perencanaan Tata Ruang, serta pengendalian pemanfaatan ruangnya.

> Bagi Mahasiswa Planologi

Agar dalam mengambil tugas akhir nanti, dapat mengambil tema mengenai pengendalian pemanfaatan ruang melalui instrumen peraturan zonasi atau perizinan, dan diharapkan dapat melakukan penelitian lebiih lanjut dikemudian hari

\section{DAFTAR PUSTAKA}

[1] BAPPEDA. 2012. Laporan Penyusunan RDTR Kecamatan Rasanae Barat 2012-2028. Kota Bima

[2] BPS. 2015. Kecamatan Rasanae Barat Dalam Angka 2016. Rasanae Barat. BPS Kota Bima

[3] Muta'ali, Luthfi. 2013. Penataan Ruang Wilayah dan Kota. Yogyakarta: BPFG Universitas Gadjah Mada.

[4] Peraturan Menteri Pekerjaan Umum Nomor : 17/Prt/M/2009. Pedoman penyusunan Rencana Tata Ruang Wilayah Kota. Jakarta 